\title{
COMUNNICAÇÃO
}

\author{
[Communication]
}

\section{Streptococcus agalactiae associado à meningoencefalite e infecção sistêmica em tilápia-do-nilo (Oreochromis niloticus) no Brasil}

\author{
[Streptococcus agalactie associated to meningoencefalitis and systemic infection from tilapia \\ (Oreochromis niloticus) in Brazil]
}

\author{
H.C.P. Figueiredo, D.O. Carneiro, F.C. Faria, G.M. Costa \\ Departamento de Medicina Veterinária - UFLA \\ Caixa postal 37 \\ 37200-000 - Lavras, MG.
}

\begin{abstract}
A estreptococose é uma doença septicêmica que afeta peixes de água doce (em cultivo ou livre no ambiente) e de ambientes estuarino e marinho As principais espécies envolvidas são Streptococcus iniae e Streptococcus agalactiae, com sinais clínicos à infecção e espectro de hospedeiros semelhantes (Evans et al., 2002a; Shelby et al., 2002). Outra espécie que pode estar envolvida é Streptococcus dysgalactiae do grupo C de Lancefield, recentemente relacionado à alta mortalidade devido à necrose acentuada do pedúnculo caudal e infecção sistêmica em peixes cultivados no Japão (Nomoto et al., 2004).
\end{abstract}

Streptococcus agalactiae tem sido isolado de animais homeotermos terrestres ou heterotermos aquáticos, o que indica uma ampla diversidade de hospedeiros (Evans et al., 2002a). Além disso, nos últimos anos, tem-se observado uma elevação da ocorrência de casos clínicos associados a $S$. agalactiae em diferentes regiões geográficas, o que levou o mesmo a ser considerado patógeno emergente para peixes em ambientes de água doce ou marinho (Evans et al., 2002b). S. agalactiae pode ser $\alpha$-hemolítico ou não hemolítico e é a única espécie que pertence ao grupo $B$ de Lancefield, que é uma sorogrupagem baseada em carboidratos antigênicos da parede celular (Lancefield, 1933).

S. agalactiae tem sido isolado de várias espécies de peixes doentes em surtos naturais, como

Recebido em 3 de maio de 2005

Aceito em 16 de fevereiro de 2006

E-mail: henrique@ufla.br
Notemigonus crysoleucas (Robinson et al., 1966), Brevoortia patronus, Arius felis, Mugil cephalus, Micropogonias undulatus, Dasyatis sp (Plumb et al., 1974), Fundulus grandis (Rasheed et al., 1984), tilápias híbridas (Oreochromis aureus x Oreochromis niloticus) (Eldar et al., 1995), Sparus auratus, Liza klunzigeri (Evans et al., 2002a) e Pampus argenteus (Duremdez et al., 2004). Em ensaios de infecção experimental, $S$. agalactiae foi patogênico para tilápias-do-nilo (Evans et al., 2002a).

O objetivo deste trabalho foi relatar o isolamento, a caracterização e o perfil de resistência a antibióticos de $S$. agalactiae, isolados a partir de surtos de meningoencefalite em tilápia-do-nilo no Brasil.

Foram analisadas tilápias provenientes de duas pisciculturas distintas com histórico de surtos com alta mortalidade e sinais neurológicos em animais adultos. $\mathrm{Na}$ piscicultura 1 , destinada à produção de alevinos, localizada no estado de Minas Gerais, o acometimento ocorreu em tanques de reprodutores. $\mathrm{Na}$ piscicultura 2, destinada à engorda e abate, localizada no estado de Espírito Santo, o surto ocorreu em tanquesrede. As características relevantes observadas em ambas as criações foram escurecimento dos peixes, exoftalmia bilateral ou unilateral em alguns animais, pequenas lesões de pele com perda de escamas e áreas de petéquias na base das nadadeiras ventrais, natação errática e em movimentos circulares, alta mortalidade e evolução rápida, com morte dois a três dias após 
o início dos sinais clínicos. Somente animais adultos de ambos os sexos foram acometidos.

Para isolamento e caracterização do agente patogênico, oito tilápias vivas de cada propriedade, apresentando sinais clínicos característicos, acondicionadas em sacos de transporte com oxigênio suplementar, foram enviadas ao laboratório. Coletaram-se de forma asséptica fragmentos de rins, baço e cérebro, que foram semeados em ágar sangue, seguindo-se a incubação a $30^{\circ} \mathrm{C}$ por até 10 dias. As colônias obtidas foram caracterizadas presuntivamente pelos testes de Gram, catalase, oxidase e crescimento em ágar Mac Conkey. Para a identificação e a classificação sorológica dos cinco isolados, classificados como Streptococcus $\mathrm{sp}$, foram utilizados os kits API $20 \mathrm{STREP}^{1} \mathrm{e}$ Slidex Latex Aglutination ${ }^{1}$, respectivamente. As cinco amostras isoladas identificados como $S$. agalactiae receberam a denominação de SA0103, SA02-03, SA03-03 na piscicultura 1, e SA04-04 e SA05-04 na piscicultura 2. A amostra SA01-03 foi isolada a partir dos rins, a SA02-03 a partir de ovas e as demais a partir de cérebro.

As cinco amostras isoladas reagiram com o antissoro do grupo B de Lancefield e de forma similar no API 20 STREP (Tab. 1).

Tabela 1. Caracterização fenotípica de $S$. agalactiae isolados de tilápias-do-nilo, oriundas de duas pisciculturas brasileiras distintas, nos testes convencionais e no API 20 STREP $^{1}$

\begin{tabular}{|c|c|c|c|c|c|}
\hline \multirow{2}{*}{ Reação } & \multicolumn{3}{|c|}{ Piscicultura 1} & \multicolumn{2}{|c|}{ Piscicultura 2} \\
\hline & SA01-03* & SA02-03* & SA03-03* & SA04-04* & SA05-04* \\
\hline Gram & + & + & + & + & + \\
\hline Morfologia & Cocos & Cocos & Cocos & Cocos & Cocos \\
\hline$\beta$ - hemólise & - & - & - & - & - \\
\hline Catalase & - & - & - & - & - \\
\hline Voges-Proskauer & + & + & + & + & + \\
\hline Hidrólise do hipurato & + & + & + & + & + \\
\hline Esculina & - & - & - & + & - \\
\hline Pirrolidonil arilamidase & - & - & - & - & - \\
\hline$\alpha$ - galactosidase & - & - & - & - & - \\
\hline$\dot{\beta}$ - glucuronidase & - & - & - & - & - \\
\hline$\beta$ - galactosidase & - & - & - & - & - \\
\hline Fosfatase alcalina & + & + & + & + & + \\
\hline Leucina arilamidase & + & + & + & + & + \\
\hline Arginina dehidrolase & + & + & + & + & + \\
\hline \multicolumn{6}{|l|}{ Produção de ácido } \\
\hline Ribose & + & + & + & + & + \\
\hline L-Arabinose & - & - & - & - & - \\
\hline manitol & - & - & - & - & - \\
\hline Sorbitol & - & - & - & - & - \\
\hline Lactose & - & - & - & - & + \\
\hline Trealose & - & - & - & - & - \\
\hline Inulina & - & - & - & - & - \\
\hline Rafinose & - & - & - & - & - \\
\hline Amido & - & - & - & - & - \\
\hline Glicogênio & - & - & - & - & - \\
\hline
\end{tabular}

* denominação de isolado de S. agalactiae

O perfil bioquímico dos isolados do Brasil foi semelhante ao das amostras de $S$. agalactiae, isoladas de peixes provenientes do Kuwait (Evans et al., 2002a e Duremdez et al., 2004).

${ }^{1}$ bioMerieux, França
A susceptibilidade das amostras frente ao ácido nalidíxico, à amoxicilina, ao cloranfenicol, à eritromicina, à gentamicina, à neomicina, à norfloxacina, à tetraciclina e à sulfonamida foi determinado pelo método de Bauer-Kirby, utilizando-se ágar Mueller Hinton ${ }^{2}$ suplementado

${ }^{2}$ Difco - EUA 
com 5\% de sangue desfibrinado de eqüino (National...1990). As amostras bacterianas foram resistentes ao ácido nalidíxico, à gentamicina e à neomicina. A resistência à norfloxacina foi variável: três amostras foram resistentes (SA0103, SA02-03 e SA03-03), uma apresentou sensibilidade moderada (SA05-04), e uma foi sensível (SA04-04). Todas foram sensíveis à amoxicilina, ao cloranfenicol, à eritromicina, à tetraciclina e à sulfonamida. Os perfis de sensibilidade das amostras foram similares aos observados em $S$. agalactiae isolados de peixes cultivados no Kuwait (Evans et al., 2002a; Duremdez et al., 2004).

Observa-se que $S$. agalactiae é um patógeno emergente em pisciculturas no Brasil e que já apresenta resistência a algumas drogas. $S$. agalactiae também pode ser isolado de casos de mamite bovina e de infecções sistêmicas e meningites em seres humanos, porém a relação epidemiológica entre os microrganismos que acometem diferentes hospedeiros ainda não está estabelecida. Além disso, deve-se ressaltar que a ocorrência de tal infecção numa piscicultura de produção de alevinos pode representar a disseminação do agente para várias regiões do país, uma vez que os alevinos são vendidos para engorda em diferentes regiões geográficas e podem ser portadores assintomáticos de $S$. agalactiae.

Palavras-chave: tilápia, Streptococcus agalactiae, caracterização, antibióticos

\begin{abstract}
Streptococcus agalactiae was isolated from cultured tilapia in Brasil. All isolates reacted similarly in API 20 STREP system (bioMerieux, France) and Slidex strepto grouping Latex Aglutination test (bioMerieux, France). Bacterial isolates were submitted to the disc diffusion technique for the antimicrobial susceptibility test. Among nine tested drugs S. agalactiae samples were resistant to three-neomicin, nalidixic acid and gentamicin.
\end{abstract}

Keywords: tilapia, Streptococcus agalactiae, characterization, antibiotics

\section{REFERÊNCIAS BIBLIOGRÁFICAS}

DUREMDEZ, R.; AL-MARZOUK, A.; QASEM, J.A. et al Isolation of Streptococcus agalactiae from cultured silver pomfret, Pampus argenteus (Euphrasen), in Kuwait. J. Fish Dis., v.27, p.307-310, 2004.

ELDAR, A.; BEJERANO, Y.; LIVOFF, A. et al. Experimental streptococcal meningo-encephalitis in cultured fish. Vet. Microbiol., v.43, p.33-40, 1995.

EVANS, J.J.; KLESIUS, P.H.; GILBERT, P.M et al Characterization of $\beta$-haemolytic group B Streptococcus agalactiae in cultured seabream, Sparus auratus L., and wild mullet, Liza klunzingeri (Day), in Kuwait. J. Fish Dis., v.25, p.505-513, 2002a.

EVANS, J.J.; WIEDENMAYER, A.A.; KLESIUS, P.H. A transport system for maintenance of viability of Acinetobacter calcoaceticus, Streptococcus iniae, and Streptococcus agalactiae over varying time periods. Bull. Eur. Assoc. Fish Pathol., v.22, p. 238246, $2002 b$.

LANCEFIELD, R.C. A serological differentiation of human and others groups of hemolytic streptococci. $J$. Exp. Med., v.59, p.571-591, 1933.
NATIONAL Committee For Clinical Laboratory Studies. Performance standards for antimicrobial disk susceptibility tests, ed. Vilanova, USA: NCCLS 1990. Document M2-A4.

NOMOTO, R.; MUNASINGHE, L.I.; JIN, D-H. et al Lancefield group C Streptococcus dysgalactiae infection responsible for fish mortalities in Japan. $J$. Fish Dis., v.27, p.679-686, 2004.

PLUMB, J.A.; SCHACHTE,J.H.; GAINES, J.L. et al Streptococcus $s p$. from marine fishes along Alabama and Northwest Florida coast of the Gulf of Mexico. Trans. Am. Fisher Soc., v.103, p.358-361, 1974.

RASHEED, V.; PLUMB, J. Pathogenicity of nom haemolytic group B Streptococcus sp. in Gulf killifish, Fundulus grandis Baird \& Girard. Aquaculture, v.37, p.97-105, 1984.

ROBINSON, J.A.; MEYER, F.P. Streptococcal fish pathogen. J. Bacteriol., v.92, p.512, 1966.

SHELBY, R.A.; KLESIUS, P.H.; SHOEMAKER, C.A. et al Passive immunization of tilapia, Oreochromis niloticus (L.), with anti-Streptococcus iniae whole sera. J. Fish Dis., v.25, p.1-6, 2002. 